\title{
Selectively enhanced radiation sensitivity in prostate cancer cells associated with proteasome inhibition
}

\author{
GRAHAM WARREN $^{1}$, KRIS GRIMES $^{2}$, YONG XU $^{3}$, MAHESH KUDRIMOTI $^{1}$ and WILLIAM ST. CLAIR ${ }^{1}$ \\ Departments of ${ }^{1}$ Radiation Medicine and ${ }^{2}$ Nutritional Sciences, \\ ${ }^{3}$ Graduate Center for Toxicology, University of Kentucky, Lexington, KY, USA
}

Received September 24, 2005; Accepted November 7, 2005

\begin{abstract}
The purpose of this study is to evaluate the utility of MG-132, a broad spectrum proteasome inhibitor, to selectively enhance radiation sensitivity in prostate cancer without affecting normal surrounding urothelial tissue. PC3 prostate cancer cells and normal URO-tsa bladder epithelial cells were treated with or without MG-132 and exposed to 0 , 2,4 , or 6 Gy radiation. Cell viability and clonogenic survival assays were performed, and nuclear factor kappa-B (NF-кB) activity was evaluated with electrophoretic mobility shift assay (EMSA). MG-132 was associated with decreased cell viability (between $24 \%$ and $33 \%$ ) and clonogenic survival (between $71 \%$ and $88 \%$ ) alone and in combination with radiation in PC3 cells. MG-132 had no effect on cell viability or clonogenic survival following radiation in URO-tsa cells. Constitutive and radiation-induced NF- $\mathrm{\kappa B}$ binding activity was higher in PC3 cells compared with URO-tsa cells. Furthermore, MG-132 at concentrations associated with reductions in cell viability and clongenic survival inhibited $\mathrm{NF}-\kappa \mathrm{B}$ binding activity in PC3 cells with no effect in UROtsa cells. These results provide strong evidence that proteasome inhibition and concomitant $\mathrm{NF}-\kappa \mathrm{B}$ inhibition can be used to selectively enhance tumor radiation sensitivity in prostate cancer without affecting normal surrounding bladder tissue.
\end{abstract}

\section{Introduction}

Prostate cancer is the most commonly diagnosed cancer and the second leading cause of cancer death afflicting men in the United States (1). Radiotherapy in the form of external beam radiation and interstitial brachytherapy are well established and commonly employed as curative therapy for locally confined prostate cancer. Radiation is also commonly used

Correspondence to: Dr William St. Clair, Department of Radiation Medicine, University of Kentucky, 800 Rose Street, Lexington, KY 40536, USA

E-mail: stclair@uky.edu

Key words: prostate, PC3, urothelial, URO-tsa, proteasome, inhibition, NF- $\mathrm{kB}$, prostate, MG-132, radiation for salvage therapy in individuals who have failed radical prostatectomy; however, radiation therapy for primary or salvage treatment can be associated with impotence, urethral stricture, radiation cystitis, and radiation proctitis. Improved response to therapy and improved quality of life by reducing morbidity are current areas of interest in prostate cancer research.

Proteasomes are multi-subunit cellular structures responsible for the non-lysosomal degradation of most intracellular proteins and molecules including proteins involved in transcriptional regulation, stress response, survival, and response to external stimuli such as inflammation and hormonal regulation $(2,3,13,14)$. Tumor suppressor gene and oncogene products known to interact with the proteasome include APC, RB1, RAS, MYC, FOS, ABL and many others demonstrating involvement in a wide variety of tumors and tissues. Proteasome inhibition has been demonstrated to increase differentiation, decrease proliferation, increase sensitivity to chemotherapy, and increase radiation sensitivity in numerous tumors and cancer cell lines $(4-7,13)$. Proteasome inhibition is also known to modulate the activity of nuclear factor kappa-B (NF-кB), a transcription factor associated with regulation of apoptosis, angiogenesis, inflammation, cellular stress response, and tumor survival. The proteasome can affect $\mathrm{NF}-\kappa \mathrm{B}$ by degrading the inhibitory subunit and allowing active NF- $\mathrm{KB}$ to translocate to the nucleus and modulate transcription $(8,15,16)$.

Proteasome inhibition has been demonstrated to increase tumor cell death, enhance chemotherapy, and increase radiation sensitivity in prostate cancer cells (5,9-11). MG-132, a broad spectrum proteasome inhibitor, decreased bombesininduced angiogenesis in PC3 cells concomitant with NF-кB inhibition implicating proteasomal regulation of NF- $\mathrm{KB}$ as a potential mechanism of inhibiting tumor progression (10). Furthermore, proteasomal inhibition with saquinavir, a human immunodeficiency virus-1 proteasome inhibitor, sensitized PC3 cells to radiation at doses associated with NF- $\kappa \mathrm{B}$ inhibition (5). These studies support the hypothesis that decreased NF-кB activity through proteasome inhibition could result in decreased tumor growth and radiation survival.

Selective enhancement of radiation sensitivity in tumor cells without affecting surrounding normal tissues could be utilized to reduce morbidity associated with radiation. The purpose of this study was to evaluate the potential utility of proteasome inhibition in modulating NF- $\mathrm{\kappa B}$ activity and 


\section{PC3 Cell Viability}

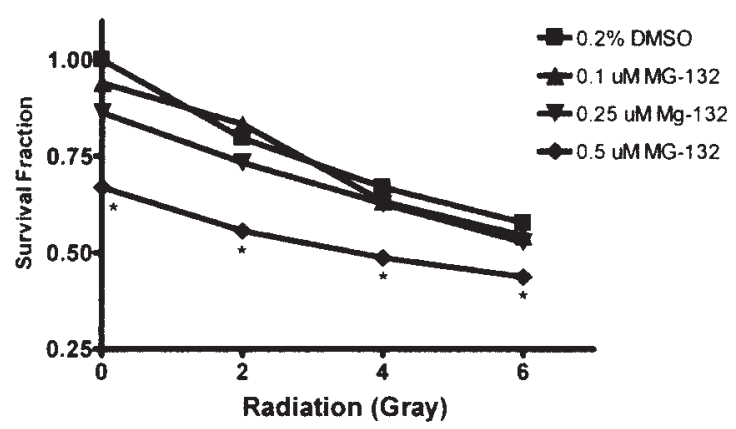

PC3 Colony Survival

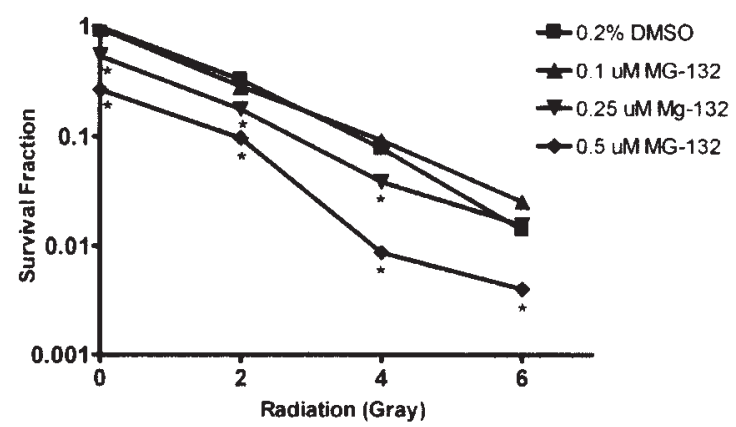

URO-tsa Cell Viability

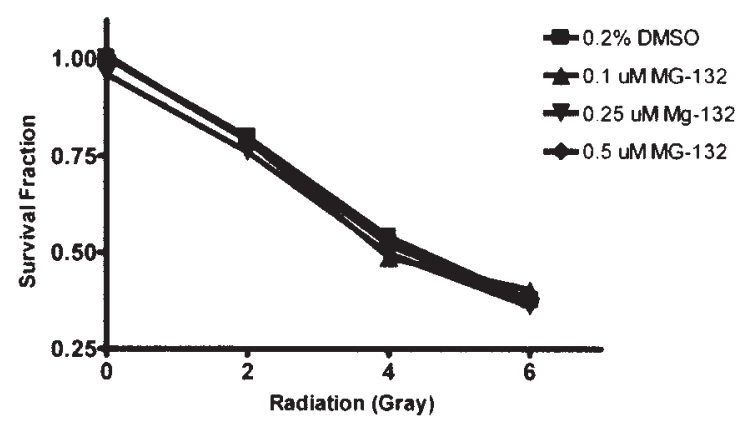

URO-tsa Colony Survival

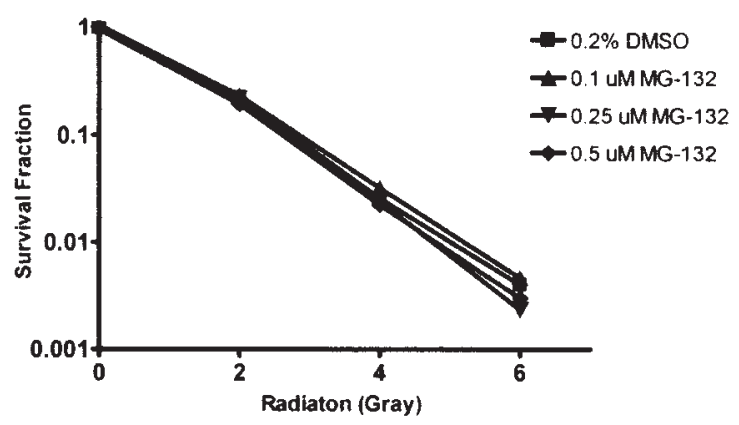

Figure 1. The effects of MG-132 on cell viability and clonogenic survival in PC3 and URO-tsa cells. Cells were treated with MG132 for 2 h prior to irradiation with $0,2,4$, or 6 Gy and cell viability was measured $72 \mathrm{~h}$ following radiation exposure. Colonies for clonogenic survival were counted 10 days after plating for PC3 cells and 12 days after plating for URO-tsa cells. *Denotes statistically significant differenced from DMSO-treated controls in each radiation dose $(\mathrm{p}<0.05)$.

selectively enhancing radiation sensitivity in the p53 null PC3 prostate cancer cell line without affecting radiation sensitivity in the non-tumorigenic urothelial cell line UROtsa (12). If the radiation sensitivity of prostate cancer cells can be selectively enhanced without affecting urothelial cells, this evidence could be used to promote clinically relevant studies to enhance radiation response in prostate cancer without affecting the adjacent normal bladder epithelium, thereby improving the treatment of prostate cancer without sacrificing quality of life as related to urinary function

\section{Materials and methods}

Materials. PC3 cells were obtained from ATCC (Rockville, MD), and URO-tsa cells were a kind gift from Dr Nyseo Unimye (Department of Urology, Virginia Commonwealth University). RPMI media was obtained from Invitrogen Gibco (Carlsbad, CA). Fetal bovine serum (FBS) and penicillin/streptomycin were obtained from Sigma-Aldrich (St. Louis, MO). MG-132 was obtained from Calbiochem (LaJolla, CA). Protein concentration reagant was obtained from Bio-Rad (Hercules, CA). Oligonucleotides for electrophoretic mobility shift assays (EMSA) were obtained from Promega (Madison, WI). Radiation was delivered using a Faxitron RX-650 X-ray source (Wheeling, IL) and operated at $125 \mathrm{kV}$ and $5 \mathrm{~mA}$ with $1 \mathrm{~mm}$ of aluminum filtration.

Cell viability assay. PC3 cells and URO-tsa cells were grown in RPMI media containing $10 \%$ FBS and $1 \%$ penicillin/ streptomycin. T25 flasks were plated with either 200,000

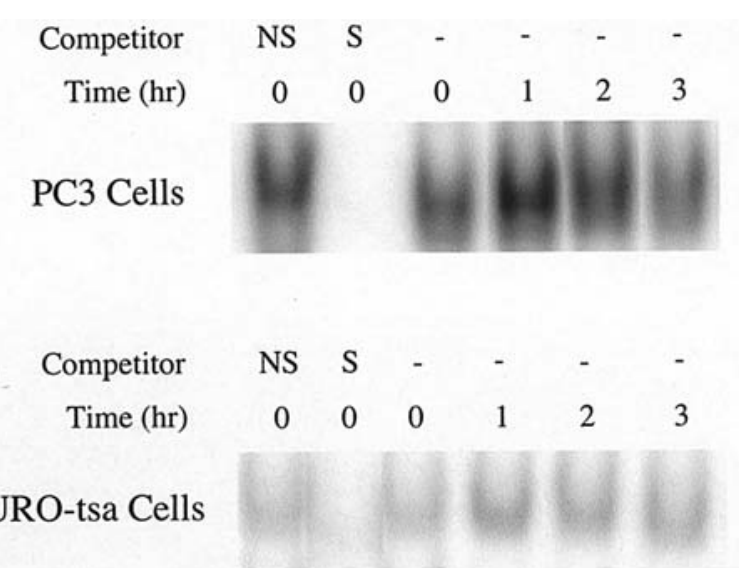

Figure 2. The effect of MG-132 on NF- $\mathrm{KB}$ activity in PC3 and URO-tsa cells following $6 \mathrm{~Gy}$ irradiation. Cells were treated with 0 (sham) or $6 \mathrm{~Gy}$ irradiation and collected 1,2 , and $3 \mathrm{~h}$ following irradiation. NF- $\mathrm{\kappa B}$ activity was assessed using EMSA. Self (S) and non-self (NS) oligonucleotides were used to compete for radiolabelled $\mathrm{NF}-\kappa \mathrm{B}$ probe thereby demonstrating specificity of the probe.

PC3 cells or 400,000 URO-tsa cells and allowed to grow for 3 days in a humidified incubator supplemented with $5 \% \mathrm{CO}_{2}$ at a temperature of $37^{\circ} \mathrm{C}$. Cells were then treated with MG-132 at concentrations of $0.1,0.25$, or $0.5 \mu \mathrm{M}$ suspended in dimethylsulfoxide (DMSO to a total dose of $0.2 \%$ in each flask) or with $0.2 \%$ DMSO as a control for $2 \mathrm{~h}$ prior to treatment with $0,2,4$, or 6 Gy radiation. Medium containing DMSO or MG-132 was removed $24 \mathrm{~h}$ after irradiation, and fresh medium was introduced. Cells were allowed to grow 


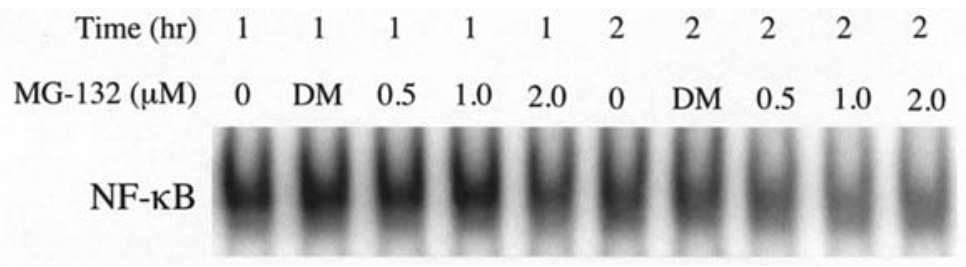

Figure 3. NF- $\kappa \mathrm{B}$ activity in irradiated PC3 cells treated with MG-132. Cells were treated with RPMI (0), DMSO (DM), or 0.5, 1.0 , or 2.0 $\mu$ M MG-132 at 2 h prior to irradiation with $6 \mathrm{~Gy}$. Cells were collected and EMSA performed to evaluate NF-кB activity at 1 and $2 \mathrm{~h}$ following irradiation.

for a total of $72 \mathrm{~h}$ following irradiation. Cell viability was determined using Trypan blue staining with a BeckmanCoulter ViCell A cell counter (Beckman-Coulter, Fullerton, CA). Relative survival rates were obtained by comparing viable cell counts compared with DMSO-treated controls without irradiation.

Clonogenic survival assay. Cells were maintained as described above and plated on T25 flasks at concentrations of 200 , 1600 , and 3200 cells per flask. Cells were plated $24 \mathrm{~h}$ prior to MG-132 treatment. Treatments with MG-132 and radiation were performed as described above. The cells were assayed for colony forming ability. After 10-12 days incubation in drug-free medium, the cells were fixed and stained with $0.5 \%$ crystal violet in methanol. Colonies with $>50$ cells were counted as clonogenic survivors. Survival fractions were obtained according to standard protocol by comparing cell counts with plating efficiency of untreated controls.

Electrophoretic mobility shift assay (EMSA). Confluent PC3 cells or URO-tsa cells were treated with MG-132 and radiation as described above. Cells were harvested by removing medium, scraping cells into a small volume of phosphate-buffered saline (PBS), centrifugation, and another washing with PBS. Cells were then resuspended in buffer containing $10 \mathrm{mM}$ HEPES-KOH, $1.5 \mathrm{mM} \mathrm{MgCl} 2,10 \mathrm{mM} \mathrm{M} \mathrm{KCl,} 0.2 \mathrm{mM}$ PMSF, $0.5 \mathrm{mM}$ dithiothreitol, $5 \mathrm{mM} \mathrm{NaF}, 1 \mathrm{mM} \mathrm{Na}_{3} \mathrm{VO}_{4}$, leupeptin, aprotinin, and pepstatin. Cells were incubated on ice, and lysed with 10\% NP-40. Lysates were centrifuged, supernatant removed, and lysates were resuspended in salt solution containing $10 \mathrm{mM}$ HEPES-KOH, $1.5 \mathrm{mM} \mathrm{MgCl}_{2}$, $0.42 \mathrm{mM} \mathrm{NaCl}, 35 \%$ glycerol, $0.2 \mathrm{mM}$ PMSF, $0.5 \mathrm{mM}$ dithiothreitol, $0.2 \mathrm{mM}$ EDTA, $5 \mathrm{mM} \mathrm{NaF}, 1 \mathrm{mM} \mathrm{Na}_{3} \mathrm{VO}_{4}$, leupeptin, aprotinin, and pepstatin, and incubated on ice. Cells were centrifuged and the supernatant removed represented nuclear extracts. For EMSAs, nuclear extracts from three separate experiments were combined to provide an accurate representation of NF- $\mathrm{\kappa B}$ activity. Protein concentrations of nuclear extracts were obtained according to the method of Bradford (17).

To evaluate NF- $\mathrm{B}$ activity, EMSAs were performed according to methods described by Promega (www.promega. com). Briefly, $15 \mu \mathrm{g}$ of protein from each sample was incubated on ice with binding buffer containing $20 \%$ glycerol, $5 \mathrm{mM} \mathrm{MgCl}_{2}, 2.5 \mathrm{mM}$ EDTA, $2.5 \mathrm{mM}$ dithiothreitol, poly $\mathrm{dI}-\mathrm{dC}$, and ${ }^{32} \mathrm{P}-$ labeled double-stranded consensus oligonucleotide specific for NF-кB. To show specificity, controls without MG-132 or radiation treatment were incubated with 100-fold excess competitors of non-radiolabelled NF-кB consensus (self) and non-self sequences. The sequence for the NF- $\mathrm{kB}$ consensus oligonucleotide are 5'-AGTTGAGGG GACTTTCCCAGG-3' and 3'-TCAACTCCCCTGAAA GGGTCC-5'. Nuclear extract incubated with radiolabelled oligonucleotides were loaded onto a $4 \%$ polyacrylamide gel and run at $120-130 \mathrm{~V}$ for $90-120 \mathrm{~min}$.

Statistical analysis. Results were compared using SPSS version 10 with analysis of variance between DMSO-treated controls and MG-132 treatments for each radiation dose.

\section{Results}

For all experiments, both PC3 and URO-tsa cells were maintained on RPMI media containing $10 \%$ FBS and $1 \%$ penicillin/streptomycin. PC3 cells demonstrated an average doubling time of $20 \mathrm{~h}$ and URO-tsa cells doubled every $33 \mathrm{~h}$. To evaluate tumorigenicity of PC3 and URO-tsa cells, 4 million cells were injected into the hind limbs of nude mice $(n=4)$. Tumors formed in $4 / 4$ mice injected with PC3 cells and grew to the point of necessitating euthanization according to IACUC protocols. No tumors formed in any of 4 mice injected with URO-tsa cells by 6 months after injection. DMSO treatment had no observable effect on cell viability, plating efficiency, or NF-кB activity in PC3 or URO-tsa cells.

The effects of MG-132 on cell viability following irradiation are shown in Fig. 1. Cell viability decreased in a dose-dependent fashion with increasing radiation doses for both PC3 and URO-tsa cells. Whereas cell viability after 2 Gy radiation in DMSO-treated PC3 cells was $80 \%$ in both PC3 and URO-tsa cells, URO-tsa cell viability was $38 \%$ after 6 Gy radiation compared with $58 \%$ in PC3 cells. PC3 cells demonstrated reduced cell viability with $0.5 \mu \mathrm{M}$ MG-132 treatment for all doses of radiation, as well as in cells without radiation treatment $(\mathrm{p}<0.05, \mathrm{n}=3)$. Reductions in cell viability compared to DMSO-treated controls ranged from $24 \%$ at $6 \mathrm{~Gy}$ to $33 \%$ at $0 \mathrm{~Gy}$. In contrast, the same concentrations of MG-132 had no effect on cell viability alone or following radiation treatment in URO-tsa cells.

Clonogenic survival in PC3 and URO-tsa cells were comparable to findings observed with cell viability (Fig. 1). Survival fractions at 2 Gy were 0.33 in PC3 cells and 0.22 in URO-tsa cells. The $0.5 \mu \mathrm{M}$ MG-132 treatment reduced survival fractions in PC3 cells at all doses of radiation between $71 \%$ and $88 \%$. Furthermore, $0.25 \mu \mathrm{M} \mathrm{MG}-132$ reduced survival fractions in PC3 cells at 0,2 , and 4 Gy radiation (between $46 \%$ and 51\%). MG-132 had no effect on survival fractions in URO-tsa cells at any radiation dose.

The effect of radiation on $\mathrm{NF}-\kappa \mathrm{B}$ activity evaluated by EMSA is shown in Fig. 2. PC3 cells demonstrated increased $\mathrm{NF}-\kappa \mathrm{B}$ activity with a peak at $1 \mathrm{~h}$ following irradiation with 


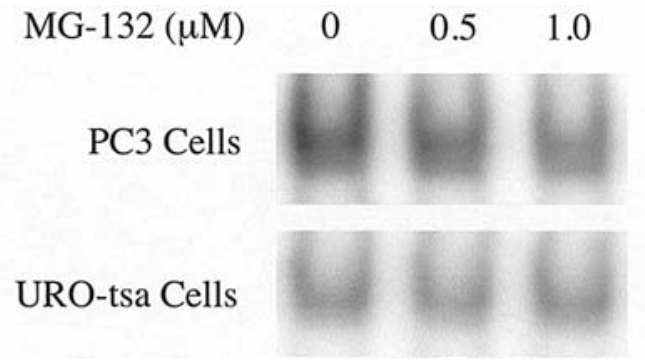

Figure 4. The effect of MG-132 on NF-кB activity in PC3 and URO-tsa cells following irradiation. PC3 and URO-tsa cells were treated with $0,0.5$, or $1.0 \mu \mathrm{M}$ MG-132 $2 \mathrm{~h}$ prior to irradiation with $6 \mathrm{~Gy}$. Cells were collected and EMSA performed to evaluate NF- $\mathrm{KB}$ activity $2 \mathrm{~h}$ following $6 \mathrm{~Gy}$ irradiation.

6 Gy. A trend toward baseline NF-кB activity was observed at $3 \mathrm{~h}$ following irradiation. URO-tsa cells demonstrated a similar pattern with decreased relative NF-кB activity compared with PC3 cells.

To evaluate the effects of MG-132 treatment on NF-кB activity following irradiation with $6 \mathrm{~Gy}, \mathrm{PC} 3$ cells were treated $2 \mathrm{~h}$ prior to $6 \mathrm{~Gy}$ irradiation with MG-132 at concentrations ranging from from 0 to $2.0 \mu \mathrm{M}$ (Fig. 3). PC3 cells treated with MG-132 demonstrated a decrease in radiation-induced NF- $\kappa \mathrm{B}$ activity with $2.0 \mu \mathrm{M}$ MG-132 $1 \mathrm{~h}$ following irradiation; however, a dose-dependent decrease in NF- $\mathrm{B}$ activity was observed $2 \mathrm{~h}$ after irradiation. A decrease in $\mathrm{NF}-\kappa \mathrm{B}$ activity at $2 \mathrm{~h}$ following irradiation was noted with MG-132 concentrations as low as $0.5 \mu \mathrm{M}$.

To compare the effects of MG-132 treatment on NF-кB activity following irradiation, PC3 and URO-tsa cells were treated with increasing doses of MG-132 (Fig. 4). NF-кB activity $2 \mathrm{~h}$ following irradiation was decreased in a dosedependent manner in PC3 cells. MG-132 had no effect on $\mathrm{NF}-\kappa \mathrm{B}$ activity in URO-tsa cells. A similar dose-dependent decrease in $\mathrm{NF}-\kappa \mathrm{B}$ activity was noted in PC3 cells at $3 \mathrm{~h}$ following irradiation with no effect on URO-tsa cells (data not shown).

\section{Discussion}

The present studies demonstrate that proteasome inhibition can selectively enhance radiation sensitivity in PC3 cells with no effect on normal URO-tsa cells. Cell viability and clonogenic survival assays clearly demonstrate that MG-132 can additively decrease cell survival following radiation in PC3 cells without affecting URO-tsa cells. Furthermore, MG-132 treatments at the same concentrations associated with enhanced radiation sensitivity produced dose-dependent reductions in NF- $\mathrm{KB}$ activity in PC3 cells with no observable changes on NF- $\mathrm{BB}$ activity in URO-tsa cells. These results are consistent with the hypothesis that reduced $\mathrm{NF}-\kappa \mathrm{B}$ activity by proteasomal inhibition is a potential mechanism of selectively enhancing radiation sensitivity in prostate cancer cells.

Constitutive NF- $\mathrm{KB}$ was located as an inactive form bound to an inhibitory subunit in the cytoplasm of cells $(8,15,16)$. Inhibitory kappa $\mathrm{B}(\mathrm{I} \kappa \mathrm{B})$ or an inhibitory $\mathrm{NF}-\kappa \mathrm{B}$ subunit p100 are constitutively bound to $\mathrm{NF}-\kappa \mathrm{B}$ rendering the protein inactive in the cytoplasm of cells. Activation of NF- $\kappa \mathrm{B}$ by various stimuli, including inflammation, stress and radiation, involves degradation of the inhibitory subunit and translocation of activated NF- $\mathrm{KB}$ to the nucleus to regulate transcription. The proteasome is responsible for the degradation of IкB, as well as proteolytic cleavage of the p100 subunit resulting in activation of $\mathrm{NF}-\kappa \mathrm{B}(2,3,14)$. Consequently, proteasome inhibition results in decreased degradation of the inhibitory subunits providing a mechanism of preventing translocation of activated NF- $\mathrm{\kappa B}$ into the nucleus.

The increase in radiation sensitivity with MG-132 in PC3 cells is consistent with previous studies demonstrating reduced survival in MG-132-treated HD-My-Z Hodgkin cells following radiation administration (18). A 3-h preincubation with $50 \mu \mathrm{M}$ MG-132 decreased survival fractions of HD-My-Z cells following radiation treatment; however, whereas MG-132 was associated with increased apoptosis, there was no effect on constitutive NF- $\mathrm{\kappa B}$ activity. Unfortunately, no evidence of the effects of radiation with or without MG-132 treatment was provided in HD-My-Z cells. Furthermore, although specific inhibition of NF- $\mathrm{KB}$ binding activity using a dominant negative $\mathrm{I} \kappa \mathrm{B} \alpha$ construct was associated with complete

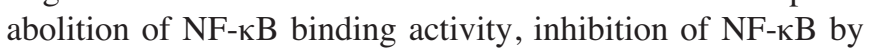
dominant negative $\mathrm{I} \kappa \mathrm{B} \alpha$ did not affect radiosensitivity, suggesting that inactivation of $\mathrm{NF}-\kappa \mathrm{B}$ by $\mathrm{I} \kappa \mathrm{B} \alpha$ alone is insufficient for enhanced radiosensitivity.

Proteasome inhibition with 2-3 h pretreatment of 50-60 $\mu \mathrm{M}$ saquinavir, a human immunodeficiency virus-1 proteasome inhibitor that specifically inhibits the $26 \mathrm{~S}$ proteasomal subunit, sensitized PC3 and DU-145 prostate cancer cells to radiation (5). Inhibition of clonogenic survival by saquinavir correlated with inhibition of $\mathrm{NF}-\kappa \mathrm{B}$ activity following radiation treatment and is consistent with the inhibition demonstrated herein with MG-132. In contrast to the absence of effect in saquinavirtreated cells at 0 Gy with no post-radiation saquinavir exposure, the inhibition of survival fraction in PC 3 cells at 0 Gy radiation in this study could be due to the $24 \mathrm{~h}$ post-radiation MG-132 exposure.

Studies demonstrate that PC3 cells have a significantly higher constitutive NF- $\mathrm{KB}$ activity and proteasome activity than other cell lines evaluated including HD-My-Z Hodgkin cells, LnCaP human prostate cancer cells, SW 1088 astrocytoma cells, ECV 304 bladder carcinoma cells, and A549 non-small cell cancer cells (18). Increased NF-кB activity and concomitant-increased constitutive interleukin-6 expression has also been observed in PC3 and DU-145 prostate cancer cells (19). Compared with URO-tsa cells, PC3 cells further reflect a significant relative increase in constitutive NF- $\kappa \mathrm{B}$ activity. The significantly increased constitutive activity in PC3 cells could be associated with several tumor-specific survival advantages that may be responsive to the effects of proteasome inhibition.

No studies to date have evaluated the effects of radiation or proteasome inhibition on URO-tsa cells. Though URO-tsa cells were originally grown in F-12 media containing epidermal growth factor, insulin, and hydrosortisone, URO-tsa cells grew well in RPMI media as described above. To standardize treatments between PC3 and URO-tsa cells, both cell types were grown in identical RPMI media containing FBS and penicillin/streptomycin, thereby eliminating potential confounding variables such as growth factor and steroid 
involvement in radiation response. URO-tsa cells were continuously maintained through 50 passages until growth was arrested and cells stopped dividing. Evaluation of tumorigenicity of URO-tsa cells grown in RPMI media demonstrated no tumors in all 4 animals observed for 6 months after 4 million URO-tsa cells were implanted. Compared with PC3 cells, URO-tsa cells demonstrated low constitutive and radiation-induced NF-кB activity. Studies herein further demonstrate that proteasome inhibition had no significant effect on clonogenic survival or NF- $\mathrm{KB}$ activity after radiation in URO-tsa cells.

Specific mechanisms of $\mathrm{NF}-\kappa \mathrm{B}$ activation by radiation are currently a rapidly expanding field of research. Ionizing radiation has been demonstrated to induce $\mathrm{NF}-\kappa \mathrm{B}$ via phosphorylation of serine residues 32 and 36 of IкB $\alpha$ by IкB kinase, but ultraviolet light leads to the activation of NF- $\mathrm{kB}$ without phosphorylation at the same residues. However, both ionizing and ultraviolet radiation-induced $\mathrm{NF}-\kappa \mathrm{B}$ activation was inhibited by proteasome inhibition (20). U251 glioblastoma cells were treated with radiation, and cellular fractions were isolated to evaluate the effects of MG-132 on I $\mathrm{B} \alpha$ degradation. Results demonstrated that MG-132 inhibited degradation of the insoluble subcellular fraction plasma membrane associated IкB $\alpha$ leading to the inhibition of radiation-induced NF- $\mathrm{\kappa B}$ activity, suggesting that cellular localization of signaling pathways is important in radiationinduced $N F-\kappa B$ activation (21). It is of further note that $\mathrm{NF}-\kappa \mathrm{B}$ is composed of multiple subunits with mechanisms of regulation and effects of specific induction that are currently an active area of evolving research. Specific mechanisms of radiation-induced $\mathrm{NF}-\kappa \mathrm{B}$ activation and tumor survival will require thorough investigation of signaling pathways, cellular localization, and specific NF- $\mathrm{KB}$ target genes.

The potential implications of results derived from the present study are significant. Results demonstrated that prostate cancer cells can be selectively sensitized with associated inhibition of NF- $\mathrm{NB}$ activity using proteasome inhibition without affecting surrounding urothelial tissue. The inclusion of proteasome inhibitors in the treatment of prostate cancer may be a means to increase the therapeutic advantage of radiation therapy with respect to prostate cancer over normal adjacent tissues. Currently, great efforts are being made on the development of various forms of conformal radiation methods to increase the given dose to the tumor, while limiting the radiation dose to adjacent structures. The study herein is the first to demonstrate in a culture system that manipulation of NF- $\mathrm{KB}$ via proteasome inhibition coupled with radiation can achieve preferential sensitization of a tumor cell compared to a normal anatomically adjacent tissue. This combination of radiation and proteasome inhibition yields the same desired clinical outcome as conformal radiation therapy. Furthermore, the manipulation of NF- $\mathrm{KB}$ by methods such as proteasome inhibition could be coupled with conformal radiation delivery, thereby potentially improving the therapeutic advantage of both modalities.

\section{Acknowledgements}

Supported in part by a Kentucky Lung Cancer Research Grant (4-65453).

\section{References}

1. Crawford ED: Epidemiology of prostate cancer. Urology 62: 3-12, 2003.

2. Pajonk F and McBride: WH The proteasome in cancer biology and treatment. Radiation Res 156: 447-459, 2001.

3. Voorhees PM, Dees EC, O'Neil B and Orlowski RZ: The proteasome as a target for cancer therapy. Clin Cancer Res 9: 6316-6325, 2003.

4. Pati S, Pelser CB, Dufraine J, et al: Antitumorigenic effect of HIV protease inhibitor ritonavir: inhibition of Kaposi sarcoma. Blood 99: 3771-3779, 2002.

5. Pajonk F, Himmelsbach J, Riess K, et al: The human immunodeficiency virus (HIV)-1 proteasome inhibitor saquinavir inhibits proteasome function and causes apoptosis and radiosensitization in non-HIV-associated human cancer cells. Cancer Res 62: 5230-5235, 2002.

6. Ikezoe T, Daar ES, Hisatake J, et al: HIV-1 protease inhibitors decrease proliferation and induce differentiation of human myelocytic leukemia cells. Blood 96: 3553-3559, 2000.

7. Hochwald SN, Lind DS, Malaty J, et al: Antineoplastic therapy in colorectal cancer through proteasome inhibition. Am Surg 69: 15-23, 2003.

8. Orlowski RZ and Baldwin AS: NF- $\kappa \mathrm{B}$ as a therapeutic target in cancer. Trends Mol Med 8: 385-389, 2002.

9. An J, Sun YP, Adams J, et al: Drug interactions between the proteasome inhibitor bortezomib and cytotoxic chemotherapy, tumor necrosis factor (TNF) alpha, and TNF-related apoptosisinducing ligand in prostate cancer. Clin Cancer Res 9: 4537-4545, 2003.

10. Levine L, Lucci JA, Pasdrak B, et al: Bombesin stimulates nuclear factor kappa $\mathrm{B}$ activation and expression of proangiogenic factors in prostate cancer cells. Cancer Res 63: 3495-3502, 2003.

11. Herrmann JL, Briones F, Brisbay S, et al: Prostate carcinoma cell death resulting from inhibition of proteasome activity is independent of functional $\mathrm{Bcl}-2$ and $\mathrm{p} 53$. Oncogene 17: 2889-2999, 1998.

12. Rossi MR, Masters JR, Park S, et al: The immortilized UROtsa cell line as a potential cell culture model of human urothelium. Environ Health Perspect 109: 801-808, 2001.

13. Cusack JC: Rationale for the treatment of solid tumors with the proteasome inhibitor bortezomib. Cancer Treat Rev 29: 21-31, 2003.

14. Adams J: The proteasome: structure, function, and role in the cell. Cancer Treat Rev 29: 3-9, 2003.

15. Aggarwal BB: Nuclear factor-kappaB: the enemy within. Cancer Cell 6: 203-208, 2004.

16. Shishodia S and Aggarwal BB: Nuclear factor-kappa B: a friend or foe in cancer? Biochem Pharmacol 68: 1071-1080, 2004.

17. Bradford MM: A rapid and sensitive method for the quantitation of microgram quantities of protein utilizing the principle of protein-dye binding. Anal Biochem 72: 248-254, 1976.

18. Pajonk F, Pajonk K and McBride WH: Apoptosis and radiosensitization of hodgkin cells by proteasome inhibition. Int $\mathrm{J}$ Radiat Oncol Biol Phys 47: 1025-1032, 2000.

19. Zerbini LF, Wang Y, Cho JY and Libermann TA: Constitutive activation of nuclear factor kappaB p50/p65 and Fra-1 and JunD is essential for deregulated interleukin 6 expression in prostate cancer. Cancer Res 63: 2206-2215, 2003.

20. Li N and Karin M: Ionizing radiation and short wavelength UV activate NF-kappaB through two distinct mechanisms. Proc Natl Acad Sci USA 95: 1301-1307, 1998.

21. Russell JS and Tofilon PJ: Radiation-induced activation of nuclear factor-kappaB involves selective degradation of plasma membrane-associated I(kappa)B(alpha). Mol Cell Biol 13: 3431-3440, 2002. 